\title{
Kinetics of Carbon Dioxide with Tertiary Amines in Aqueous Solution
}

The reaction of $\mathrm{CO}_{2}$ with TEA, DMMEA, and DEMEA has been studied at $293,303,318$ and $333 \mathrm{~K}$. All the kinetic experiments were carried out in a stirred cell reactor operated with a flat, smooth and horizontal gas-liquid interface. A numerical method, which describes mass transfer accompanied by reversible chemical reactions, has been applied to infer rate constants from the experimental data. It is argued that the contribution of the $\mathrm{CO}_{2}$ reaction with $\mathrm{OH}^{-}$to the observed reaction rate may have been overestimated in most literature on tertiary amine kinetics as serious depletion of $\mathrm{OH}^{-}$toward the gas-liquid interface usually occurs.

For all the amines studied, the reaction order in amine was found to be about one for each temperature investigated. This is in good agreement with the base catalysis mechanism proposed by Donaldson and Nguyen (1980). All kinetic data could be summarized reasonably well in one Brønsted relationship.

\section{Introduction}

Alkanolamine solutions are used frequently to remove acidic components, such as $\mathrm{H}_{2} \mathrm{~S}, \mathrm{CO}_{2}$, and $\mathrm{COS}$, from natural and refinery gases. Industrially important alkanolamines for this operation are the secondary amines, diethanolamine (DEA) and diisopropanolamine (DIPA), and the tertiary amine $N$-methyldiethanolamine (MDEA). Usually aqueous solutions of these alkanolamines are applied, but combined solvents like water and sulfolane in the Shell Sulfinol process are also used (Kohl and Riesenfeld, 1979). Often there is no need to remove $\mathrm{CO}_{2}$, therefore selective absorption of the sulfur compounds may lower the costs of the treating process considerably (Blauwhoff et al., 1985).

Selective absorption of the sulfur compounds, particularly $\mathrm{H}_{2} \mathrm{~S}$, is achieved by reducing the reaction rate of $\mathrm{CO}_{2}$. Generally this reaction rate for tertiary amines is much lower than that for primary and secondary amines, which explains the increasing popularity of tertiary amines for selective absorption. Also the processes based on sterically hindered (secondary) amines, like the Exxon Flexsorb process, seem to be suitable for this purpose. To improve the selectivity, extensive knowledge of the reaction kinetics of $\mathrm{CO}_{2}$ with alkanolamines is needed.

The reaction of $\mathrm{CO}_{2}$ with tertiary amines can be described satisfactorily with the base-catalysis reaction mechanism proposed by Donaldson and Nguyen (1980). Experimental data for
TEA and MDEA support this mechanism (Blauwhoff et al., 1984; Barth et al., 1984; Yu et al., 1985; Versteeg and Van Swaaij, 1988b; Tomcej and Otto, 1989; Crooks and Donnellan, 1990). On the basis of this reaction mechanism, Versteeg and Van Swaaij (1988b) showed that a linear relationship may exist between the second-order reaction rate constant and the $p K a$ value of various alkanolamines at $293 \mathrm{~K}$.

In the present work, the reaction between $\mathrm{CO}_{2}$ and triethanolamine (TEA), dimethylmonoethanolamine (DMMEA) and diethylmonoethanolamine (DEMEA) has been studied at 293 , 303,318 and $333 \mathrm{~K}$. A numerical model which describes gas absorption accompanied by parallel reversible chemical reactions was used to interpret the experimental data. It shows that the $\mathrm{OH}^{-}$contribution to the observed reaction rate has been overestimated in most literature on the reaction of $\mathrm{CO}_{2}$ with tertiary amines. Consequently, previously published data of Blauwhoff et al. (1984) and of Versteeg and Van Swaaij (1988b) have been reinterpreted.

\section{Reaction Mechanism}

Donaldson and Nguyen (1980) proposed the following reaction mechanism for the reaction of $\mathrm{CO}_{2}$ with tertiary amines:

$$
\mathrm{CO}_{2}+R_{1} R_{2} R_{3} \mathrm{~N}+\mathrm{H}_{2} \mathrm{O} \leftrightarrow \mathrm{HCO}_{3}^{-}+R_{1} R_{2} R_{3} \mathrm{NH}^{+}
$$

This reaction mechanism is essentially a base-catalyzed 
hydratation of $\mathrm{CO}_{2}$, and the mechanism implies that tertiary amines cannot react directly with $\mathrm{CO}_{2}$. This was confirmed by Versteeg and Van Swaaij (1988b) who studied the absorption of $\mathrm{CO}_{2}$ into a waterfree solution of MDEA and ethanol. They found that $\mathrm{CO}_{2}$ was only physically absorbed, which is in agreement with the proposed reaction mechanism.

At extremely high $\mathrm{pH}(\approx 13)$, a direct reaction between $\mathrm{CO}_{2}$ and the alcohol groups of TEA has been reported by Jørgensen and Faurholt (1954); however, at lower $\mathrm{pH}$ values $(\mathrm{pH}<11)$, the rate of this reaction can be neglected.

Apart from reaction 1 , the following reactions also occur in aqueous solutions:

$$
\begin{aligned}
& \mathrm{CO}_{2}+\mathrm{OH}^{-} \leftrightarrow \mathrm{HCO}_{3}^{-} \\
& \mathrm{CO}_{2}+\mathrm{H}_{2} \mathrm{O} \leftrightarrow \mathrm{H}_{2} \mathrm{CO}_{3}
\end{aligned}
$$

In aqueous amine solutions, the contribution of the uncatalyzed reaction 3 to the overall reaction rate is usually negligible.

The reaction of $\mathrm{CO}_{2}$ with TEA and especially MDEA has been studied quite extensively. For aqueous TEA solutions at $298 \mathrm{~K}$, there is a good agreement between the results of various authors and techniques (Donaldson and Nguyen, 1980; Barth et al., 1981; Blauwhoff et al., 1984). The rate constant at $298 \mathrm{~K}$ reported by Crooks and Donnellan (1990) is somewhat lower than the value reported by the previous authors. The observed reaction rates reported by Sada et al. (1976) and Hikita et al. (1977) are much higher. As is shown by Versteeg et al. (1990), this is likely due to small amounts of primary and secondary amine impurities which can have an overruling effect on the observed reaction rates, especially at very low $\mathrm{CO}_{2}$ loadings. Recently Sada et al. (1989) published data on the absorption of $\mathrm{CO}_{2}$ in nonaqueous TEA solutions. They reported a reaction between $\mathrm{CO}_{2}$ and TEA in these nonaqueous solutions. This is in clear contradiction with the proposed reaction mechanism and the work of Versteeg and Van Swaaij (1988b). Moreover, the rate constants reported by Sada et al. (1989) are much too high in comparison to data of various authors and techniques for aqueous TEA solution and even considerably higher than the data reported for the stronger base MDEA in aqueous solutions.

The reaction between $\mathrm{CO}_{2}$ and $\mathrm{MDEA}$ in aqueous solution at $298 \mathrm{~K}$ was studied by Barth et al. (1984), Blauwhoff et al. (1984), and Crooks and Donnellan (1990). Kinetic data at various temperatures were provided by $\mathrm{Yu}$ et al. (1985), Versteeg and Van Swaaij (1988b), and Tomcej and Otto (1989). Among all these authors, fair agreement exists on the activation temperature and observed reaction rates. Only Haimour et al. (1987) reported an activation temperature which is almost twice the value of the activation temperature reported by other authors.

Versteeg and Van Swaaij (1988b) also studied the reaction of $\mathrm{CO}_{2}$ with DMMEA at $293 \mathrm{~K}$ and with triethylamine (TREA) at $292 \mathrm{~K}$. In contradiction with Donaldson and Nguyen (1980), they did observe base catalysis of the $\mathrm{CO}_{2}$ hydratation for TREA. The reaction between $\mathrm{CO}_{2}$ and DEMEA was studied at $303 \mathrm{~K}$ by Spaninks et al. (1988) and at $323 \mathrm{~K}$ by $\mathrm{Kim}$ and Savage (1987).

A linear relationship at $293 \mathrm{~K}$ between the logarithm of the second-order reaction rate constant $k_{2}$ and the acid dissociation constant $p K a$ of various amines was suggested by Versteeg and Van Swaaij (1988b).

\section{Experimental Procedure}

The experiments were carried out in a stirred cell reactor with a smooth horizontal gas-liquid interface. The operation was batchwise with respect to both gas and liquid phase. The experimental setup used was identical to that of Blauwhoff et al. (1984) and Versteeg and Van Swaaij (1988a) and is shown in Figure 1. A detailed description of the experimental procedure is given by Blauwhoff et al. (1984).

During an experiment, the pressure decrease of pure carbon dioxide is recorded as a function of time. Based on mass balances for both gas and liquid phase the following expression for the carbon dioxide flux can be derived:

$$
J_{\mathrm{CO}_{2}}=m_{\mathrm{CO}_{2}} k_{1, \mathrm{CO}_{2}} E P \mathrm{CO}_{2} / R T
$$

The enhancement factor for $E$ is equal to $H a$ if pseudofirstorder conditions are fulfilled:

$$
2<H a \ll E^{\infty}
$$

with:

$$
\begin{gathered}
H a=\frac{\sqrt{k_{\mathrm{ov}} D_{\mathrm{CO}_{2}}}}{\mathrm{k}_{1}} \\
E^{\infty}=\sqrt{\frac{D_{\mathrm{CO}_{2}}}{D_{\mathrm{Am}}}}+\sqrt{\frac{D_{\mathrm{Am}}}{D_{\mathrm{CO}_{2}}}} \frac{[\mathrm{Am}] R T}{m_{\mathrm{CO}_{2}} P_{\mathrm{CO}_{2}}}
\end{gathered}
$$

Expression 7, however, is valid only for irreversible reactions. As was shown by Versteeg et al. (1989), considerable diffusion limitation may occur in the case of reversible reactions even though condition 5 is fulfilled ( $E^{\infty}$ calculated according to relation 7 ). Only reversible reactions with extremely high equilibrium constants and at very low conversions can be considered irreversible, as only in that case the backward reaction rate is negligible in comparison with the forward reaction rate. Hence, interpretation of absorption experiments concerning reversible reactions should be extremely careful as there is no explicit way to determine if diffusion limitation may be neglected.

The reaction of $\mathrm{CO}_{2}$ with tertiary alkanolamines cannot be assumed irreversible, as the equilibrium constants are not extremely high and tend to decrease considerably with increas-

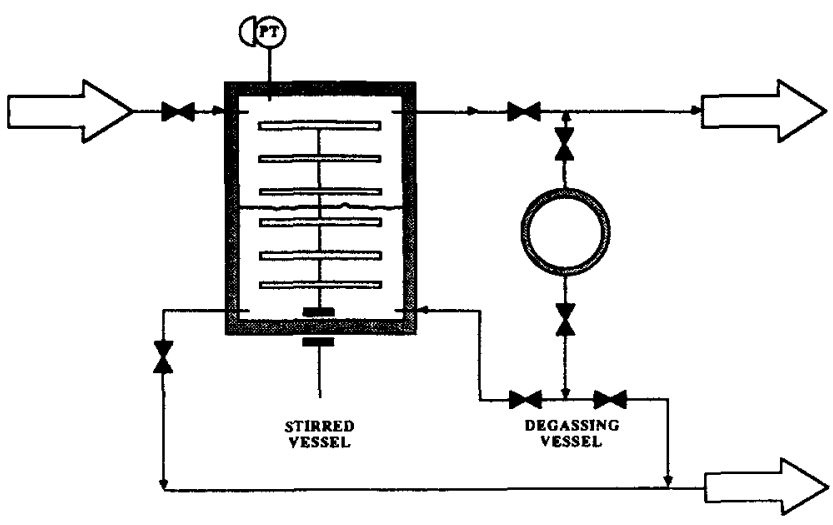

Figure 1. Experimental setup. 
ing temperature (Littel et al., 1990). Therefore, a numerical fitting procedure was applied to obtain the true overall reaction rate constants. This fitting procedure consisted of a numerical flux model, based on Higbie's penetration theory, which describes the phenomenon of mass transfer accompanied by parallel reversible chemical reactions. All relevant reactions, which take place if $\mathrm{CO}_{2}$ is absorbed in an aqueous solution of a tertiary amine, were incorporated in the flux model (reactions 1 , 2, 8 and 10). Model equations and initial and boundary conditions were similar to those applied by Glasscock and Rochelle (1989). Numerical techniques used were identical to those applied by Versteeg et al. (1989).

For all kinetic experiments, reaction rate constants at two different $\mathrm{CO}_{2}$ loadings were obtained by minimizing the difference between experimentally determined and numerically calculated specific absorption rates. This method offers a reliable way to interpret gas absorption experiments, in which mass transfer is accompanied by a reversible reaction even if the experiments were not carried out in the pseudofirst-order regime. The difference between the reaction rate constants obtained from the numerical interpretation method and the reaction rate constants obtained from the pseudofirst-order interpretation was up to $15 \%$, although relatively low $\mathrm{CO}_{2}$ pressures were applied in the experiments.

As $\mathrm{CO}_{2}$ reacts with the alkanolamine, it is not possible in general to determine the solubility and diffusivity directly. In view of the similarities with regard to configuration, molecular volume, and electronic structure, $\mathrm{N}_{2} \mathrm{O}$ is often used as a nonreacting gas to estimate the physical properties of $\mathrm{CO}_{2}$. In the present study, the solubility of $\mathrm{CO}_{2}$ was determined by means of this $\mathrm{CO}_{2}-\mathrm{N}_{2} \mathrm{O}$ analogy (Laddha et al., 1981; Versteeg and Van Swaaij, 1988c). The diffusivity of $\mathrm{CO}_{2}$ was estimated using the $\mathrm{CO}_{2}-\mathrm{N}_{2} \mathrm{O}$ analogy and the modified Stokes-Einstein relationship reported by Versteeg and Van Swaaij (1988c). The liquid-phase mass transfer coefficient could be estimated from the correlation developed by Versteeg et al. (1987). Viscosity and $\mathrm{N}_{2} \mathrm{O}$-solubility of aqueous TEA, DMMEA and DEMEA solutions are reported in Table 1 and 2, respectively.

For all kinetic experiments, $\mathrm{CO}_{2}$ pressures and amine loadings were typically $0.05-0.20$ bar and $0.3-1.5 \%$, respectively.

DMMEA and DEMEA were obtained from Merck; and TEA was obtained from Janssen Chimica. All alkanolamines were p.a. quality and used as received.

Table 1. Polynomial Coefficients for the Calculation of the Viscosity of Aqueous Alkanolamine Solutions at Various Temperatures*

\begin{tabular}{lccccc}
\hline Amine & $\begin{array}{c}\text { Temp. } \\
\mathrm{K}\end{array}$ & $\begin{array}{c}{[\mathrm{Am}]_{\max }} \\
\mathrm{mol} \cdot \mathrm{m}^{-3}\end{array}$ & $a_{0}$ & $10^{3 *} a_{1}$ & $10^{6 *} a_{2}$ \\
\hline TEA & 293 & $2,408.3$ & 1.043 & 0.191 & 0.373 \\
TEA & 303 & $2,398.1$ & 0.831 & 0.153 & 0.236 \\
TEA & 318 & $2,381.6$ & 0.608 & 0.124 & 0.155 \\
TEA & 333 & $2,362.7$ & 0.474 & 0.105 & 0.095 \\
\hline DMMEA & 303 & $2,387.4$ & 0.812 & 0.183 & 0.103 \\
DMMEA & 318 & $2,367.9$ & 0.597 & 0.141 & 0.059 \\
DMMEA & 333 & $2,345.9$ & 0.469 & 0.105 & 0.032 \\
DEMEA & 293 & $2,369.2$ & 1.032 & 0.346 & 0.379 \\
DEMEA & 303 & $2,354.1$ & 0.820 & 0.258 & 0.207 \\
DEMEA & 318 & $2,331.6$ & 0.602 & 0.178 & 0.121 \\
DEMEA & 333 & $2,305.2$ & 0.472 & 0.130 & 0.069 \\
\hline
\end{tabular}

$*=a_{0}+a_{1}[\mathrm{Am}]+a_{2}[\mathrm{Am}]^{2}$
Table 2. Polynomial Coefficients for Calculating Solubility of $\mathrm{N}_{2} \mathrm{O}$ in Aqueous Alkanolamine Solutions at Various Temperatures*

\begin{tabular}{lcccccr}
\hline Amine & $\begin{array}{c}\text { Temp. } \\
\mathrm{K}\end{array}$ & $\begin{array}{c}{[\mathrm{Am}]_{\max }} \\
\mathrm{mol} \cdot \mathrm{m}^{-3}\end{array}$ & $a_{0}$ & $10^{3 *} a_{1}$ & $10^{6 *} a_{2}$ & $10^{9 *} a_{3}$ \\
\hline TEA & 293 & $3,193.0$ & 0.678 & -0.047 & & \\
TEA & 303 & $2,372.5$ & 0.547 & -0.045 & & \\
TEA & 318 & $2,419.9$ & 0.404 & -0.032 & 0.024 & -0.007 \\
TEA & 333 & $2,426.8$ & 0.310 & -0.001 & & \\
\hline DMMEA & 303 & $2,382.5$ & 0.541 & -0.027 & & \\
DMMEA & 318 & $2,396.4$ & 0.400 & -0.003 & & \\
DMMEA & 333 & $2,496.4$ & 0.310 & -0.004 & 0.005 & \\
DEMEA & 293 & $2,434.0$ & 0.684 & -0.077 & 0.011 & \\
DEMEA & 303 & $2,443.6$ & 0.544 & -0.071 & 0.036 & -0.006 \\
DEMEA & 318 & $2,361.8$ & 0.402 & -0.002 & -0.008 & 0.005 \\
DEMEA & 333 & $2,277.7$ & 0.308 & -0.010 & 0.020 & \\
\hline
\end{tabular}

${ }^{*} m=a_{0}+a_{1}[\mathrm{Am}]+a_{2}[\mathrm{Am}]^{2}+a_{3}[\mathrm{Am}]^{3}$

\section{$\mathrm{OH}^{-}$Contribution}

As described above, the two main reactions which occur when $\mathrm{CO}_{2}$ is absorbed in aqueous solutions of tertiary amines are:

$$
\begin{gathered}
\mathrm{CO}_{2}+R_{1} R_{2} R_{3} \mathrm{~N}+\mathrm{H}_{2} \mathrm{O} \leftrightarrow \mathrm{HCO}_{3}^{-}+R_{1} R_{2} R_{3} \mathrm{NH}^{+} \\
\mathrm{CO}_{2}+\mathrm{OH}^{-} \leftrightarrow \mathrm{HCO}_{3}^{-}
\end{gathered}
$$

Hence, absorption experiments to determine the kinetics of reaction 1 should be interpreted very carefully as the reaction of $\mathrm{CO}_{2}$ with $\mathrm{OH}^{-}$may have a significant contribution to the observed reaction rate. In most literature on $\mathrm{CO}_{2}$ kinetics with tertiary amines in aqueous solutions, it is assumed that reactions 1 and 2 are parallel pseudofirst-order reactions (Blauwhoff et al., 1984; Kim and Savage, 1987; Versteeg and Van Swaaij, $1988 \mathrm{~b}$; Tomcej and Otto, 1989). This assumption is based on the consideration that the equilibrium reaction between free amine and $\mathrm{H}_{2} \mathrm{O}$ is instantaneous with respect to mass transfer as it involves only a proton transfer:

$$
R_{3} \mathrm{~N}+\mathrm{H}_{2} \mathrm{O}=R_{3} \mathrm{NH}^{+}+\mathrm{OH}^{-}
$$

This leads to the concentration profiles as depicted in Figure 2. If reactions 1 and 2 are assumed to be parallel pseudofirst-

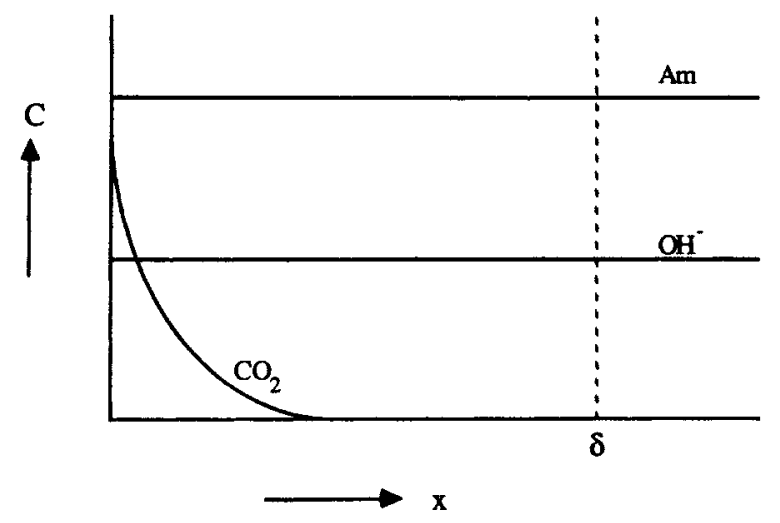

Figure 2. Concentration profiles for reactions 1 and 2 with pseudofirst-order reactions. 
order reactions, the following expression of the observed reaction rate constant $k_{\mathrm{ov}}$ can be derived:

$$
k_{\mathrm{ov}}=k_{\mathrm{OH}}\left[\mathrm{OH}^{-}\right]+k_{2}[\mathrm{Am}]
$$

Usually the values of $\left[\mathrm{OH}^{-}\right]$and $[\mathrm{Am}]$ are estimated using a suitable equilibrium model. Among others, Pohorecki and Moniuk (1988) presented a correlation for $k_{\mathrm{OH}^{-}}$.

Glasscock and Rochelle (1989), however, showed that significant depletion of $\mathrm{OH}^{-}$at the interface may occur. In their excellent model, they took into account four reactions: the finite rate reactions, $\mathrm{CO}_{2}$-amine and $\mathrm{CO}_{2}-\mathrm{OH}^{-}$, and the instantaneous equilibria reactions, amine- $\mathrm{H}_{2} \mathrm{O}$ and carbonate-bicarbonate (reactions $1,2,8$ and 10$)$.

$$
\mathrm{HCO}_{3}^{-}+\mathrm{OH}^{-}=\mathrm{CO}_{3}^{2-}+\mathrm{H}_{2} \mathrm{O}
$$

Their numerical simulations showed that only at very low $\mathrm{CO}_{2}$ loadings and very low partial $\mathrm{CO}_{2}$ pressures, interpretation of kinetic experiments according to relation 9 is allowed.

In the present work, a numerical model based on the penetration theory according to Higbie was applied, in which reactions $1,2,8$ and 10 were also incorporated. There is an excellent agreement between the present model and the model of Glasscock and Rochelle (1989), although different numerical techniques were used (discretization vs. orthogonal collocation). The present model has the advantage that it can be executed on personal computers.

As already mentioned this numerical model was used to infer kinetic rate constants from the absorption experiments. From the simulations it was concluded that in all kinetic experiments the $\mathrm{OH}^{-}$depletion near the gas-liquid interface was such that the $\mathrm{OH}^{-}$contribution to the observed reaction rate was negligible. A typical concentration profile is given in Figure 3.

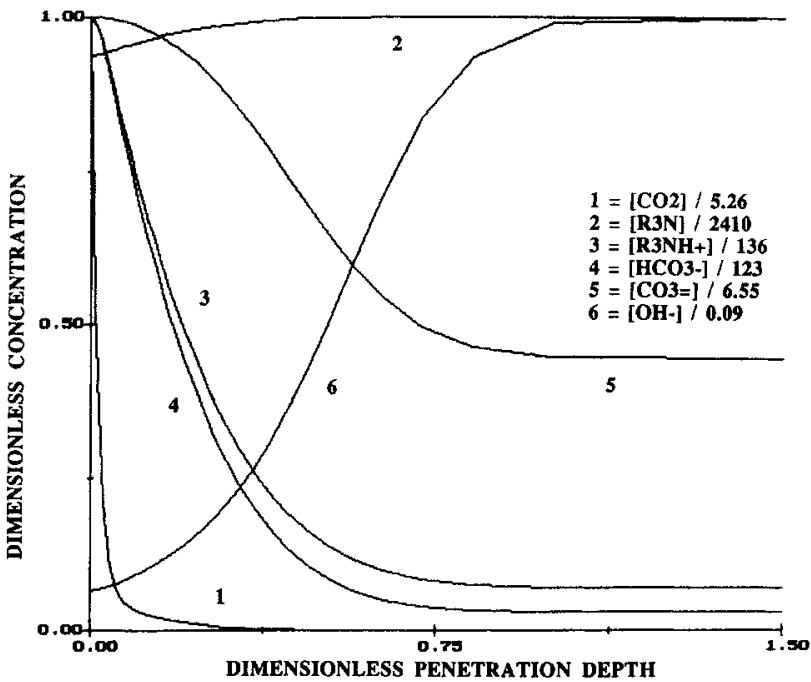

Figure 3. Typical dimensionless concentration profile calculated with the numerical model.

TEA, $293 \mathrm{~K} ;[\mathrm{Am}]=2,424 \mathrm{~mol} / \mathrm{m}^{3} ; P_{\mathrm{CO} 2}=0.17 \mathrm{bar}$; amine loading $=0.3 \%$
Summarizing, it was concluded that all kinetic experiments in the present work should be interpreted according to:

$$
k_{\mathrm{ov}}=k_{2}[\mathrm{Am}]
$$

The kinetic data reported by Blauwhoff et al. (1984) and by Versteeg and Van Swaaij (1988b), which were obtained under the same experimental conditions as applied in the present work, were reinterpreted according to Eq. 11 . The validity of this reinterpretation according to Eq. 11 was confirmed by means of the numerical fitting procedure. The values of $k_{2}$ resulting from this reinterpretation, which are for TEA and MDEA up to $35 \%$ and for TREA about $150 \%$ higher than the originally reported values, are presented in Table 3.

\section{Results}

$\mathrm{TEA}-\mathrm{H}_{2} \mathrm{O}$

No reliable data have been published on the temperature dependence of the reaction rate of $\mathrm{CO}_{2}$ with TEA in aqueous solution. Therefore, in the present work this reaction has been studied at 293, 303, 318 and $333 \mathrm{~K}$. The results of the kinetic experiments are presented in Figure 4 . As can be deduced from this figure, the reaction order in amine was about equal to 1 for all temperatures investigated. The second-order reaction rate constants which were obtained by linear regression are presented in Table 4. Figure 5 shows the temperature dependence of these rate constants. This dependence is represented by:

$$
k_{2}=1.01 * 10^{4} * \exp \left(\frac{-4,415}{T}\right)\left[\mathrm{m}^{3} \cdot \mathrm{mol}^{-1} \cdot \mathrm{s}^{-1}\right]
$$

As can be concluded from Figure 5, the agreement between the present results and the reinterpreted data of Blauwhoff et al. (1984) is very good. Also the kinetic data reported by Donaldson and Nguyen (1980) and by Barth et al. (1981) agree rather well with the present results. The rate constant observed by Crooks and Donnellan (1990) is quite low in comparison to the other literature data.

Table 3. Reinterpreted Second-Order Reaction Rate Constants

\begin{tabular}{lllll}
\hline \multicolumn{1}{c}{ Reference } & Amine & $\begin{array}{c}\text { Temp. } \\
\mathrm{K}\end{array}$ & $\mathrm{m}^{3} \cdot \mathrm{mol}^{-1} \cdot \mathrm{s}^{-1}$ & $p \mathrm{Ka}^{*}$ \\
\hline $\begin{array}{lllll}\text { Blauwhoff et al. } \\
\quad \text { (1984) }\end{array}$ & TEA & 298 & 0.0039 & 7.88 \\
\hline $\begin{array}{l}\text { Versteeg and } \\
\text { Van Swaaij (1988b) }\end{array}$ & MDEA & 293 & 0.0039 & 8.74 \\
& MDEA & 298 & 0.0051 & 8.63 \\
& MDEA & 308 & 0.0095 & 8.44 \\
& MDEA & 318 & 0.017 & 8.25 \\
& MDEA & 333 & 0.041 & 8.00 \\
\hline Versteeg and & & & & \\
$\quad$ Van Swaaij (1988b) & DMMEA & 293 & 0.0075 & 9.23 \\
\hline Versteeg and & & & & \\
$\quad$ Van Swaaij (1988b) & TREA & 292 & 0.076 & 10.81 \\
\hline
\end{tabular}

${ }^{*} K_{\mathrm{a}}$ values in $10^{3} \mathrm{~mol} \cdot \mathrm{m}^{-3}$ 


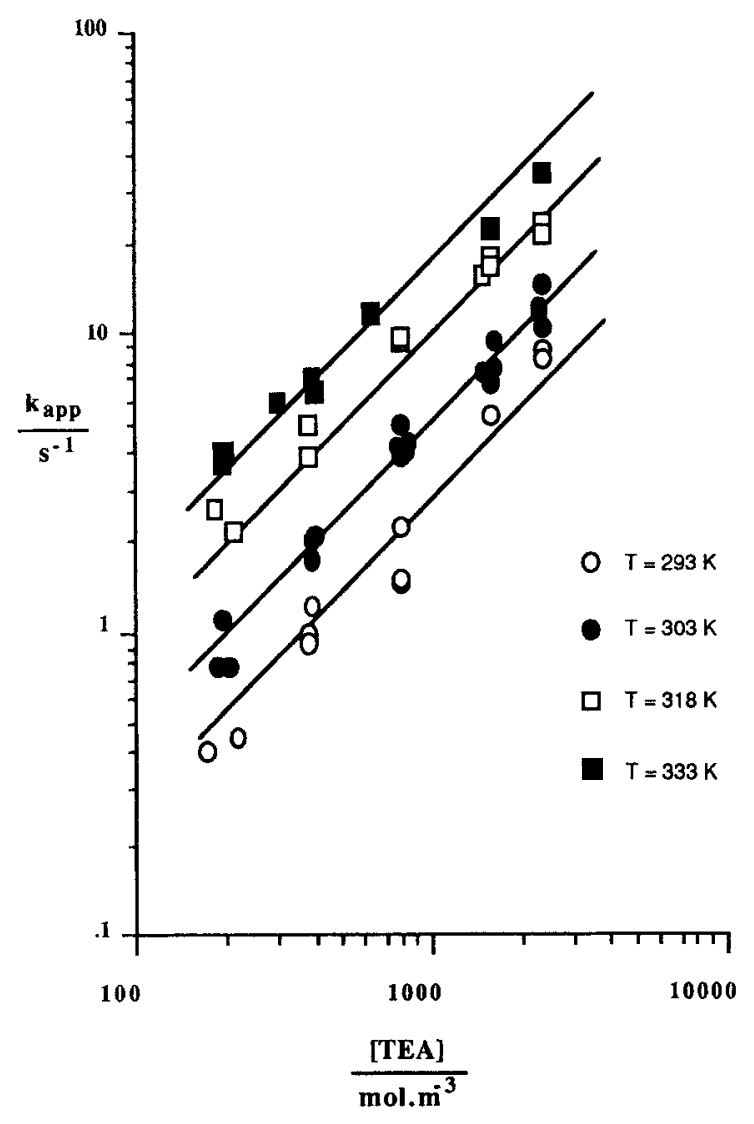

Figure 4. Experimental kinetic data for $\mathrm{TEA}-\mathrm{H}_{2} \mathrm{O}$.

\section{$M D E A-\mathrm{H}_{2} \mathrm{O}$}

Kinetic data at various temperatures for the reaction of $\mathrm{CO}_{2}$ with MDEA in aqueous solution were reported by Versteeg and Van Swaaij (1988b). These data were reinterpreted as the $\mathrm{OH}^{-}$ contribution to the overall reaction rate had been overestimated. The resulting data which are about $30 \%$ higher than the originally reported values are given in Table 3 . The temperature dependence is represented by:

$$
k_{2}=1.34 * 10^{6} * \exp \left(\frac{-5,771}{T}\right)\left[\mathrm{m}^{3} \cdot \mathrm{mol}^{-1} \cdot \mathrm{s}^{-1}\right]
$$

Table 4. Fitted Second-Order Reaction Rate Constants

\begin{tabular}{lccc}
\hline Amine & $\begin{array}{c}\text { Temp. } \\
\mathrm{K}\end{array}$ & $\begin{array}{c}\boldsymbol{k}_{2} \\
\mathrm{~m}^{3} \cdot \mathrm{mol}^{-1} \cdot \mathrm{s}^{-1}\end{array}$ & $p K \boldsymbol{a}^{*}$ \\
\hline TEA & 293 & 0.0027 & 7.98 \\
TEA & 303 & 0.0049 & 7.78 \\
TEA & 318 & 0.011 & 7.51 \\
TEA & 333 & 0.017 & 7.26 \\
\hline DMMEA & 303 & 0.023 & 8.99 \\
DMMEA & 318 & 0.055 & 8.69 \\
DMMEA & 333 & 0.12 & 8.36 \\
\hline DEMEA & 293 & 0.031 & 9.76 \\
DEMEA & 303 & 0.061 & 9.47 \\
DEMEA & 318 & 0.14 & 9.16 \\
DEMEA & 333 & 0.29 & 8.71 \\
\hline
\end{tabular}

${ }^{*} K_{a}$ values in $10^{3} \mathrm{~mol} \cdot \mathrm{m}^{-3}$

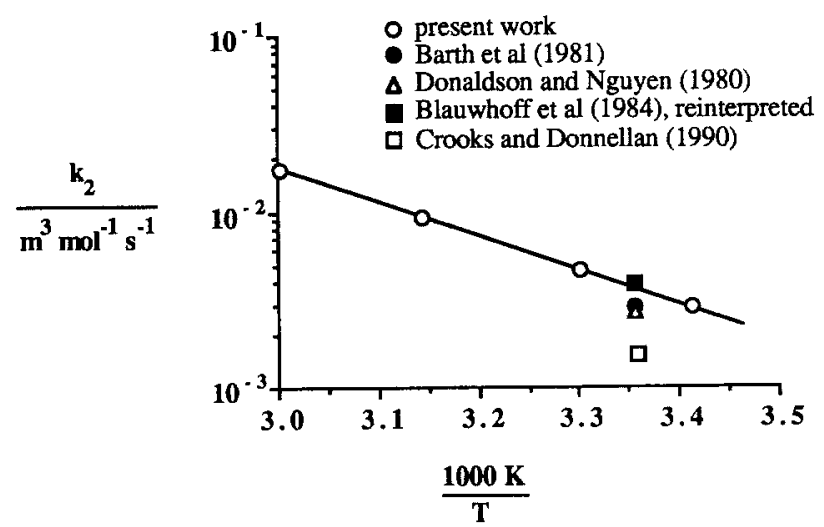

Figure 5. Arrhenius plot for $\mathrm{TEA}-\mathrm{H}_{2} \mathrm{O}$.

These data are shown in Figure 6 together with other literature data. It should be pointed out that also in the work by Yu et al., (1985), Haimour et al. (1987), and Tomcej and Otto (1989), the $\mathrm{OH}^{-}$contribution to the observed reaction rate may have been seriously overestimated. The latter two interpreted their data according to Eq. 9. From the work of $\mathrm{Yu}$ et al. (1985), it is not clear in which way the $\mathrm{CO}_{2}-\mathrm{OH}^{-}$reaction was taken into account.

Nevertheless, there exists good agreement among the results of most authors, although a wide variety of experimental techniques were used (stirred cell, wetted sphere, stopped flow with optical or conductimetric detection). Only the results of Haimour et al. (1987) are significantly lower, whereas their activation temperature is almost a factor of two higher than that reported by Yu et al. (1985), Tomcej and Otto (1989), and the reinterpreted data of Versteeg and Van Swaaij (1988b).

\section{DMMEA- $\mathrm{H}_{2} \mathrm{O}$}

Versteeg and Van Swaaij (1988b) reported kinetic data at $293 \mathrm{~K}$ for the reaction of $\mathrm{CO}_{2}$ with DMMEA in aqueous

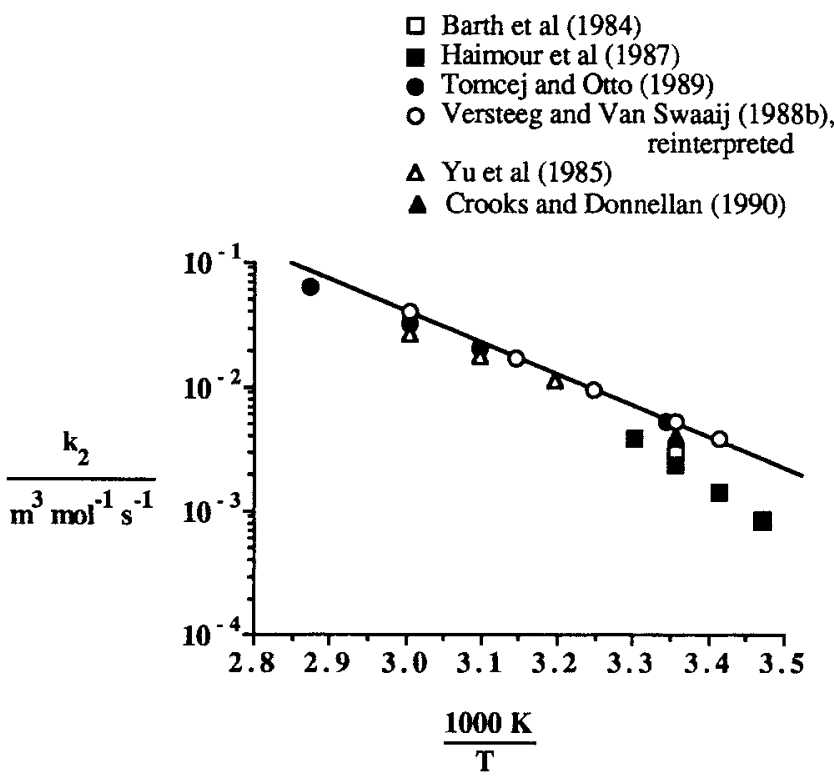

Figure 6. Arrhenius plot for MDEA- $\mathrm{H}_{2} \mathrm{O}$. 
solution. In the present work, this reaction has been studied at 303,318 and $333 \mathrm{~K}$. The experimental results are presented in Figure 7. In agreement with the reaction mechanism proposed, the experimentally found reaction order in amine is about equal to 1 for each temperature investigated. The fitted second-order reaction rate constants are reported in Table 4 . The temperature dependence of $k_{2}$ is illustrated in Figure 8 and given by:

$$
k_{2}=1.65 * 10^{6} * \exp \left(\frac{-5,479}{T}\right)\left[\mathrm{m}^{3} \cdot \mathrm{mol}^{-1} \cdot \mathrm{s}^{-1}\right]
$$

From Figure 8 it can be concluded that the agreement between the present results and the reinterpreted data of Versteeg and Van Swaaij (1988b) is fairly good.

\section{DEMEA $-\mathrm{H}_{2} \mathrm{O}$}

The kinetics of the reaction between $\mathrm{CO}_{2}$ and aqueous DEMEA solutions have been studied at 293, 303, 318 and 333 K. The experimental results are presented in Table 4 and Figure 9. From Figure 9 it can be deduced that the reaction order in amine is about equal to 1 for all temperatures investigated. This is in good agreement with the reaction mechanism proposed for tertiary amines in aqueous solution. In Table 4 the second-order rate constants obtained by means of linear regression are reported. The temperature dependence of these rate constants is represented by:

$$
k_{2}=3.36 * 10^{6} * \exp \left(\frac{-5,413}{T}\right)\left[\mathrm{m}^{3} \cdot \mathrm{mol}^{-1} \cdot \mathrm{s}^{-1}\right]
$$

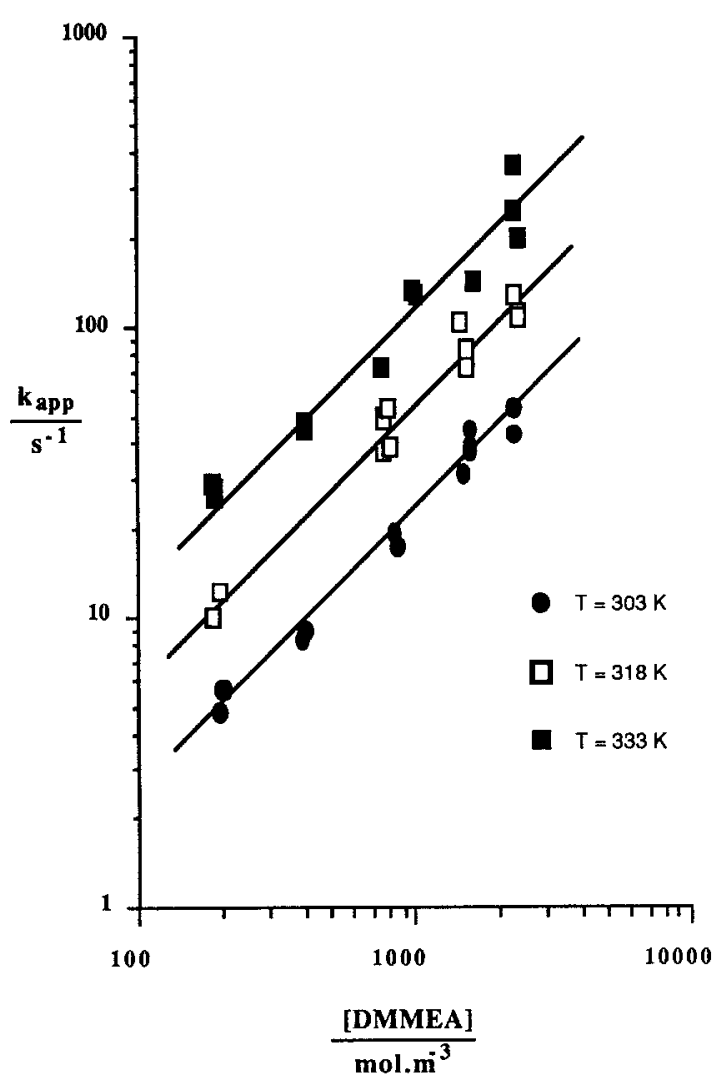

Figure 7. Experimental kinetic data for DMMEA- $\mathrm{H}_{2} \mathrm{O}$.

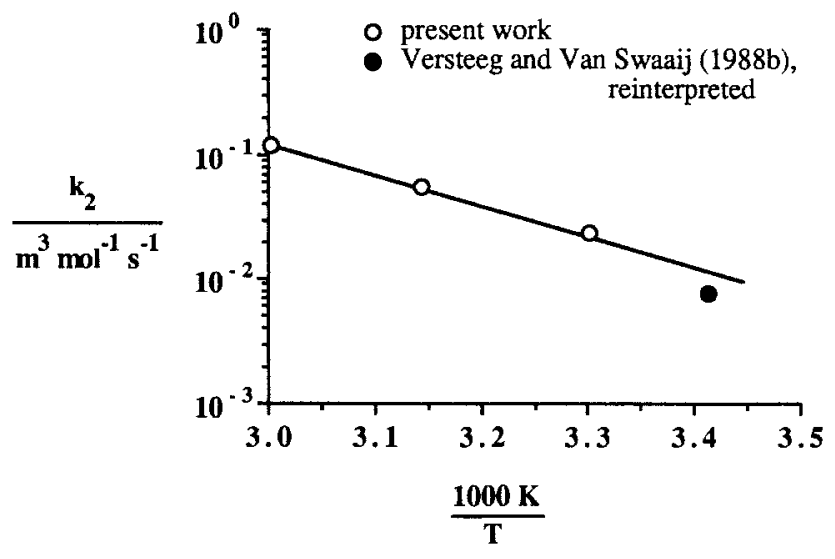

Figure 8. Arrhenius plot for DMMEA- $\mathrm{H}_{2} \mathrm{O}$.

The kinetic data presented by Spaninks et al. (1988) at $303 \mathrm{~K}$ are considerably lower than the present results (see Figure 10). This is most likely due to an overestimation of the $\mathrm{OH}^{-}$ contribution to the observed reaction rate as they probably used relation 9 to interpret their experiments.

Kim and Savage (1987) reported experimental data for the absorption of $\mathrm{CO}_{2}$ into aqueous DEMEA solutions at $323 \mathrm{~K}$. As can be concluded from Figure 10, the agreement between the present results and the results of Kim and Savage (1987) is poor. This deviation can only be explained partially from the difference in the physical data used to interpret the kinetic experiments.

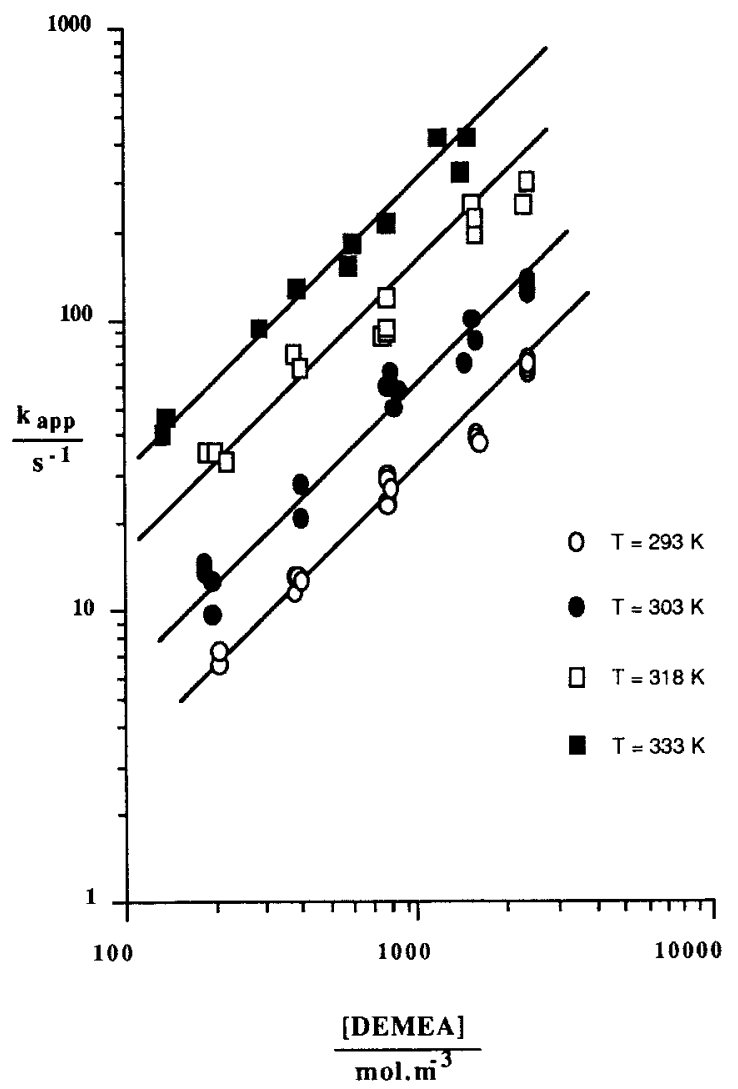

Figure 9. Experimental kinetic data for DEMEA- $\mathrm{H}_{2} \mathrm{O}$. 


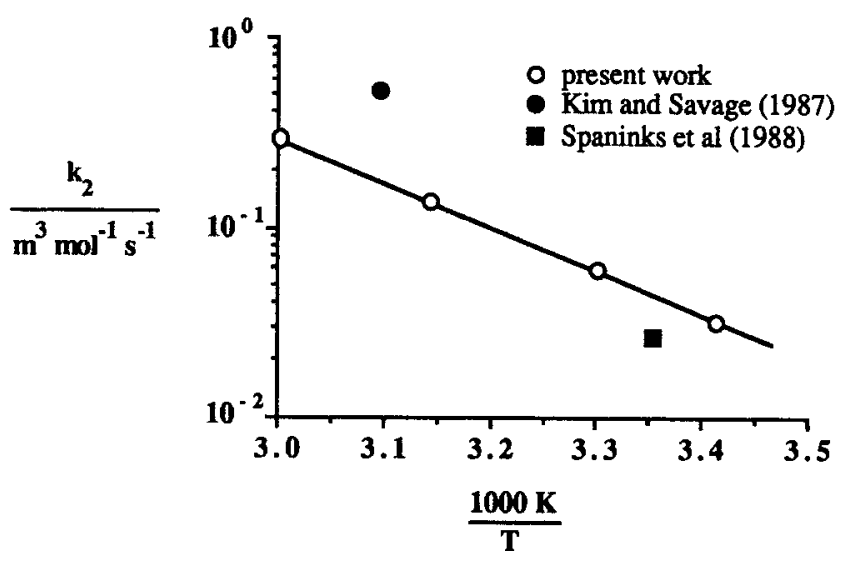

Figure 10. Arrhenlus plot for DEMEA- $\mathrm{H}_{2} \mathrm{O}$.

\section{Bronsted relationship}

Versteeg and Van Swaaij (1988b) suggested a so-called Bronsted relationship between the second-order rate constant, $k_{2}$, and the acid dissociation constant $K_{a}$. Such a relationship is in accordance with the reaction mechanism proposed by Donaldson and Nguyen (1980). In the present work it was tried to develop one Brønsted relationship for various temperatures and tertiary amines. For this purpose the kinetic data presented in Tables 3 and 4 were used as these data were obtained in the same experimental setup and the respective kinetics were derived with the aid of the numerical absorption model. The $p K a$ values for DEMEA, DMMEA, and MDEA at temperatures ranging from 293 to $333 \mathrm{~K}$ were reported recently by Littel et al. (1990). For MDEA they reported $p K a$ values which were 0.12 higher than those by Perrin (1965). This deviation was attributed to a different, more reliable standard used by Littel et al. (1990). Consequently the $p K a$ values for TEA, which were taken from Perrin (1965), were also raised by 0.12. Linear regression yielded the following Bronsted relationship:

$$
\ln k_{2}=\frac{-8,171}{T}+1.47 p K a+9.80
$$

This relation fits all kinetic data presented in Tables 3 and 4 within about $40 \%$; see also Figure 11 . This may be judged as a rather good fit considering the temperature range, $p K a$ range and the experimental errors inherent to the experimental method.

For tertiary amines for which the kinetics with $\mathrm{CO}_{2}$ in aqueous solutions have not been evaluated yet, the Bronsted relationship given by Eq. 16 offers a yardstick to estimate the kinetic rate constant from only $p K a$ and temperature measurements. In this way, new, promising amines can be screened rapidly.

\section{Conclusions}

The reaction of $\mathrm{CO}_{2}$ with TEA, DMMEA, and DEMEA has been studied in aqueous solutions at 293, 303, 318 and $333 \mathrm{~K}$. All kinetic data are in good agreement with the base-catalyzed hydratation mechanism proposed by Donaldson and Nguyen (1980).

In the determination of the kinetics of $\mathrm{CO}_{2}$ with amines from mass transfer experiments, the $\mathrm{OH}^{-}$contribution to the ob-

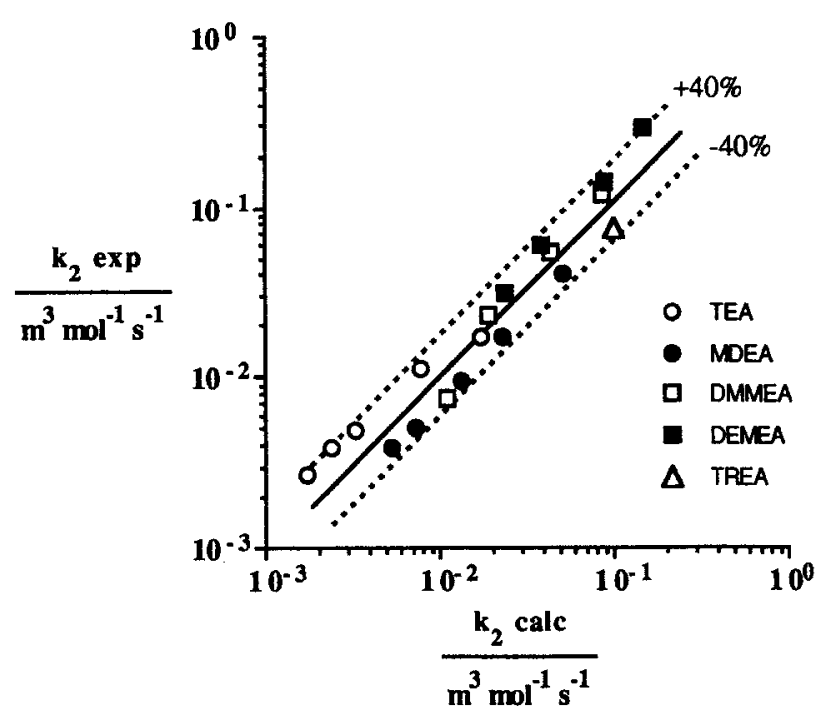

Figure 11. $k_{2}$ values: experimental v8. calculated according to Brønsted relationship (Eq. 16).

served reaction rate should be considered very carefully as serious depletion of $\mathrm{OH}^{-}$toward the gas-liquid interface may occur (Glasscock and Rochelle, 1989). A numerical model similar to that of Glasscock and Rochelle (1989) showed that this contribution is negligible for stirred cell experiments with aqueous tertiary amine solutions. As a result, the kinetic data reported by Blauwhoff et al. (1984) and Versteeg and Van Swaaij (1988b) were reinterpreted. The values of $k_{2}$ resulting from this reinterpretation are for TEA and MDEA up to 35\% and for TREA about $150 \%$ higher than the originally reported values.

A numerical model which describes gas absorption accompanied by reversible chemical reactions offers a reliable way to interpret absorption data for processes with reversible reactions.

A Br $\phi$ nsted relationship fitted all the kinetic data within about $40 \%$. This relationship can be used to estimate the reaction rate with $\mathrm{CO}_{2}$ from only $p K a$ and temperature measurements for tertiary amines which have not been evaluated yet.

\section{Acknowledgment}

These investigations were supported by the Koninklijke/Shell Laboratorium Amsterdam. We also acknowledge W. Lengton for carrying out all the amine analyses.

\section{Notation}

$$
\begin{aligned}
D & =\text { diffusivity, } \mathrm{m}^{2} \cdot \mathrm{s}^{-1} \\
E & =\text { enhancement factor } \\
E^{\infty} & =\text { maximum enhancement factor, defined in Eq. } 7 \\
H a & =\text { Hatta number, defined in Eq. } 6 \\
J & =\text { mol flux, mol } \cdot \mathrm{m}^{-2} \cdot \mathrm{s}^{-1} \\
k_{2} & =\text { second-order forward reaction rate constant, } \mathrm{m}^{3} \cdot \mathrm{mol}^{-1} \cdot \mathrm{s}^{-1} \\
K a & =\text { acid dissociation constant, mol } \cdot \mathrm{m}^{-3} \\
k_{\text {app }} & =\text { apparent pseudofirst-order reaction rate constant, } \mathrm{s}^{-1} \\
k_{\mathrm{ov}} & =\text { overall pseudofirst-order reaction rate constant, } \mathrm{s}^{-1} \\
k_{l} & =\text { liquid-phase mass transfer coefficient, } \mathrm{m} \cdot \mathrm{s}^{-1} \\
m & =\text { dimensionless solubility } \\
P & =\text { pressure, } \mathrm{Pa} \\
R & =\text { ideal gas constant, } \mathrm{J} \cdot \mathrm{mol} \mathrm{l}^{-1} \cdot \mathrm{K}^{-1} \\
T & =\text { temperature, } \mathrm{K} \\
\eta & =\text { viscosity, } \mathrm{mPa} \cdot \mathrm{s}
\end{aligned}
$$




\section{Literature Cited}

Barth, D., C. Tondre, and J.-J. Delpeuch, "Kinetics and Mechanism of the Reactions of Carbon Dioxide with Alkanolamines: a Discussion Concerning the Cases of MDEA and DEA," Chem. Eng. Sci., 39, 1753 (1984).

Barth, D., C. Tondre, G. Lappai, and J.-J. Delpeuch, "Kinetic Study of Carbon Dioxide Reaction with Tertiary Amines in Aqueous Solutions," J. Phys. Chem., 85, 3660 (1981).

Blauwhoff, P. M. M., B. Kamphuis, W. P. M. van Swaaij, and K. R. Westerterp, "Absorber Design in Sour Natural Gas Treatment Plants: Impact of Process Variables on Operation and Economics," Chem. Eng. Proc., 19, 1 (1985).

Blauwhoff, P. M. M., G. F. Versteeg, and W. P. M. van Swaaij, “A Study on the Reaction between $\mathrm{CO}_{2}$ and Alkanolamines in Aqueous Solutions," Chem. Eng. Sci., 39, 207 (1984).

Crooks, J. E., and J. P. Donnellan, "Kinetics of the Reaction between Carbon Dioxide and Tertiary Amines," J. Org. Chem., 55, 1372 (1990).

Donaldson, T. L., and Y. N. Nguyen, "Carbon Dioxide Reaction and Transportation in Aqueous Amine Membranes," Ind. Eng. Chem. Fundam., 19, 260 (1980).

Glasscock, D. A., and G. T. Rochelle, "Numerical Simulation of Theories for Gas Absorption with Chemical Reaction." AIChE J., 35, 1271 (1989).

Haimour, N., A. Bidarian, and O. C. Sandall, "Kinetics of the Reaction between Carbon Dioxide and Methyldiethanolamine," Chem. Eng. Sci., 42, 1393 (1987).

Hikita, H., S. Asai, H. Ishikawa, and M. Honda, "The Kinetics of the Reaction of Carbon Dioxide with Monoethanolamine, Diethanolamine and Triethanolamine by a Rapid Mixing Method," Chem. Eng., $J ., 13,7$ (1977).

J $\phi$ rgensen, E., and C. Faurholt, "Reactions between Carbon Dioxide and Amine Alcohols," Acta Chem. Scand., 8, 1141 (1954).

Kim, C. J., and D. W. Savage, "Kinetics of Carbon Dioxide Reaction with Diethylaminoethanol in Aqueous Solutions," Chem. Eng. Sci., 42, 1481 (1987).

Kohl, A. L., F. C. Riesenfeld, Gas Purification, Gulf Publ. (1979).

Laddha, S. S., J. M. Diaz, and P. V. Danckwerts, "The $\mathrm{N}_{2} \mathrm{O}$ Analogy: the Solubilities of $\mathrm{CO}_{2}$ and $\mathrm{N}_{2} \mathrm{O}$ in Aqueous Solutions of Organic Compounds," Chem. Eng. Sci., 36, 228 (1981).

Littel, R. J., M. Bos, and G. J. Knoop, "Dissociation Constants of Some Alkanolamines at 293, 303, 318 and 333 K," J. Chem. Eng. Data, 35, 276 (1990).
Perrin, D. D., Dissociation Constants of Organic Bases in Aqueous Solution, Butterworths, London (1965).

Pohorecki, R., and W. Moniuk, "Kinetics of Reaction between Carbon Dioxide and Hydroxyl Ions in Aqueous Electrolyte Solutions," Chem. Eng. Sci., 43, 1677 (1988).

Sada, E., H. Kumazawa, and M. A. Butt, "Gas Absorption with Consecutive Chemical Reaction: Absorption of Carbon Dioxide into Aqueous Amine Solutions," Can. J. Chem. Eng., 54, 421 (1976).

Sada, E., H. Kumazawa, Y. Ikehara, and Z. Q. Han, "Chemical Kinetics of the Reaction of Carbon Dioxide with Triethanolamine in Nonaqueous Solvents," Chem. Eng. J., 40, 7 (1989).

Spaninks, J. A. M., W. H. Hesselink, and M. M. Suenson, "Selective $\mathrm{H}_{2} \mathrm{~S}$ Removal by Mixed Solvents," AIChE Meeting, New Orleans (Mar. 6-9, 1988).

Tomcej, R. A., and F. D. Otto, "Absorption of $\mathrm{CO}_{2}$ and $\mathrm{N}_{2} \mathrm{O}$ into Aqueous Solutions of Methyldiethanolamine," $A I C h E J ., 35,861$ (1989).

Versteeg, G. F., P. M. M. Blauwhoff, and W. P. M. van Swaaij, "The Effect of Diffusivity on Gas-Liquid Mass Transfer in Stirred Vessels: Experiments at Atmospheric and Elevated Pressures," Chem. Eng. Sci., 42, 1103 (1987).

Versteeg, G. F., and W. P. M. van Swaaij, "On the Kinetics between $\mathrm{CO}_{2}$ and Alkanolamines both in Aqueous and Nonaqueous Solutions: 1. Primary and Secondary Amines," Chem. Eng. Sci., 43, 573 (1988a).

-, "On the Kinetics between $\mathrm{CO}_{2}$ and Alkanolamines both in Aqueous and Nonaqueous Solutions: II. Tertiary Amines," Chem. Eng. Sci., 43, 587 (1988b).

, "Solubility and Diffusivity of Acid Gases $\left(\mathrm{CO}_{2}, \mathrm{~N}_{2} \mathrm{O}\right)$ in Aqueous Alkanolamine Solutions," J. Chem. Eng. Data, 32, 29 (1988c).

Versteeg, G. F., J. A. M. Kuipers, F. P. H. van Beckum, and W. P. M. van Swaaij, "Mass Transfer with Complex Reversible Chemical Reactions: 1. Single Reversible Chemical Reactions," Chem. Eng. Sci., 44, 2295 (1989).

,"Mass Transfer with Complex Reversible Chemical Reactions: II. Parallel Reversible Chemical Reactions," Chem. Eng. Sci., 45, 183 (1990)

Yu, W.-C., G. Astarita, and D. W. Savage, "Kinetics of Carbon Dioxide Absorption in Solutions of Methyldiethanolamine," Chem. Eng. Sci., 40, 1585 (1985).

Manuscript received May 24, 1990, and revision received Aug. 17, 1990. 